phys. stat. sol. (a) 183, No. 2, 235-250 (2001)

\title{
Study of Alpha-Sigma Phase Transformation in Mechanically Alloyed Fe-Cr-Sn Alloys
}

\author{
B.F.O. Costa (a), G. Le Cä̈r (b), and N. Ayres de CAmpos (a) \\ (a) Physics Department of the University of Coimbra, P-3000 Coimbra, Portugal \\ (b) LSG2M, UMR CNRS 7584, Ecole des Mines, F-54042 Nancy Cedex, France
}

(Received April 3, 2000; in revised form September 20, 2000;

accepted September 21, 2000)

Subject classification: $64.70 . \mathrm{Nd}$; S1.1; S1.2

\begin{abstract}
The solubility of tin is significantly extended by mechanical alloying in near equiatomic $\mathrm{Fe}-\mathrm{Cr}$ alloys. The influences of Sn concentration and of grain size on the kinetics of formation of the $\sigma$-phase have been studied using different techniques. The $\sigma$-phase formation is much faster for as-milled alloys than it is for conventional alloys. The $\sigma$-phase formation rate decreases with the increase of Sn concentration in alloys with nanometer-sized grains as it does in coarse-grained alloys. The mechanisms which are responsible for the slowing-down of the $\alpha-\sigma$ transformation are different in both kinds of alloys.
\end{abstract}

\section{Introduction}

Binary $\mathrm{Fe}-\mathrm{Cr}$ alloys are important both from fundamental and from applied points of view because they exhibit a variety of notable and now classical phenomena which gave and still give rise to an extensive literature which is too broad to be quoted fairly in the present paper. Investigations have been naturally extended to ternary or multinary $\mathrm{Fe}-\mathrm{Cr}-$ based alloys. The latter phenomena include for instance spin and charge density waves and spin glasses on the chromium rich-side, a miscibility gap at low temperature in the central part of the equilibrium phase diagram which allows investigating phase separation by nucleation and growth or by spinodal decomposition, the formation of a sigma phase at high temperature, between about 800 and $1100 \mathrm{~K}$, in near equiatomic alloys as also found in many transition-metal binary systems and resistance to corrosion. Among the numerous applications of $\mathrm{Fe}-\mathrm{Cr}$ based alloys, we notice for instance their use in advanced nuclear reactor applications [1], due to their corrosion and heat resistance and relatively low cost. However, their properties deteriorate with sigma phase precipitation. Recently it has been found that the formation of the $\sigma$-phase in coarse-grained near equiatomic alloys can be highly retarded by purification [2] or by the presence of small amounts of Sn [3] or drastically accelerated by the addition of only 0.1 at $\%$ of $\mathrm{Ti}$, the highest rate being obtained for an addition of 0.3 at $\% \mathrm{Ti}$ [4-6].

Mechanical alloying is a solid state reaction technique used among others to extend the solubility range of an element in a solid solution or in alloys which uses high-energy ball-mills to produce these metastable alloys in the form of powders with typical micronic particles constituted of grains with a typical size of $10 \mathrm{~nm}$. The latter technique of materials synthesis offers thus the opportunity of investigating how the o-phase formation is influenced by the addition of elements beyond the maximum solubility limit at equilibrium and by a decrease of grain size, far below the classical micrometer range, with its related strong increase of the density of grain boundaries. The nanometer range 
of grain sizes is further worth being investigated as nanostructured materials are expected to exhibit improved mechanical properties at least for grain sizes larger than about $25 \mathrm{~nm}$ [7]. Tin was chosen as a ternary addition to near equiatomic alloys as recent studies showed that mechanical alloying increases the solubility of $\mathrm{Sn}$ in $\mathrm{Cr}$ [8] and in $\mathrm{Fe}[9,10]$. The extension of tin solubility in such $\mathrm{Fe}-\mathrm{Cr}$ alloys was briefly mentioned in a previous report of the study of the precipitation of the sigma phase in ascast $\mathrm{Fe}-\mathrm{Cr}-\mathrm{Sn}$ alloys [11] to which the results of the present investigation will be compared.

\section{Experimental Procedure}

\subsection{Preparation of the alloys}

The alloys were prepared by mechanically alloying mixtures of appropriate amounts of Fe $(99.9 \%$, powder, grain size $<40 \mu \mathrm{m}), \mathrm{Cr}(99.2 \%$, powder, grain size $100 \mu \mathrm{m})$ and $\mathrm{Sn}$ $(99.8 \%$, powder, grain size $<40 \mu \mathrm{m})$ using a planetary ball mill (Fritsch P-7) at a disc rotating speed of $640 \mathrm{rpm}$. The average weight of the powders was $4 \mathrm{~g}$ and the powderto-ball weight ratio was $1 / 20$. The powders were sealed in the vials under a pure argon atmosphere. Both the vials ( $45 \mathrm{ml}$ in volume) and the balls (seven balls with a diameter of $15 \mathrm{~mm}$ ) were made of hardened $\mathrm{Fe}_{87} \mathrm{Cr}_{13}$ stainless steel (with a hardness of about $63 \mathrm{HRC}$ ). The results of some milling experiments, which were performed with thermally untreated milling tools (with hardness around $35 \mathrm{HRC}$ ), will also be briefly described. The samples which were prepared using untreated and hardened vials and balls will be denoted u-samples and t-samples, respectively. The u-samples were milled for 8 $\mathrm{h}$ interrupted $30 \mathrm{~min}$ every $2 \mathrm{~h}$. The t-samples were ground for $16 \mathrm{~h}$ interrupted $15 \mathrm{~min}$ every $1 \mathrm{~h}$. Milling was interrupted to avoid excessive temperature rise of the vial and to decrease the adherence of the powders to the vials. The samples were prepared taking into account the contamination from the vial and balls to reach the sought-after final compositions of the alloys.

An $\mathrm{Fe}_{57} \mathrm{Cr}_{43}$ ingot was also milled for $16 \mathrm{~h}$, with an interruption of 15 min every hour, with hardened milling tools, l-FeCr.

For comparison, we present some results obtained on coarse-grained conventional alloys. These alloys were prepared by arc-melting appropriate amounts of commercially available pure metals (Goodfellow): Fe (purity 99.998\%), Cr (purity 99.996\%) and Sn (purity 99.999\%), under a pure argon atmosphere.

\subsection{Experimental techniques}

The compositions of the samples were determined by microprobe analysis with a Camebax SX 50 system. Scanning and transmission electron microscopies (SEM and TEM) were also used to examine the microstructures. The microscopes used were respectively a JEOL T330 under a working voltage of $20 \mathrm{kV}$ and a HITACHI H9000-NA using $300 \mathrm{kV}$. The samples, either as-milled or as-milled and heat-treated, were prepared for TEM as follows: they were slightly crushed in a mortar containing liquid nitrogen in order to fragment the samples while preventing changes due to temperature rise. After ultrasonic dispersion, some particles were collected from the suspension and placed over $\mathrm{Cu}$ grids covered with a colloid. Finally, an electrical contact was assured by evap- 
orating carbon over samples and grids. The colloid solution was prepared by mixing together formvar and chloroform.

Mössbauer spectroscopy was used to probe the local atomic structure of the alloys. ${ }^{57} \mathrm{Fe}$ Mössbauer spectra were obtained at room temperature and ${ }^{119} \mathrm{Sn}$ spectra at $160 \mathrm{~K}$, both in a transmission geometry with a constant acceleration apparatus.

The spectra were analysed with a conventional constrained Hesse-Rübatsch method [12], which extracts an hyperfine mean field distribution, $P\left(B_{\mathrm{hf}}\right)$, from an experimental spectrum, where $P\left(B_{\mathrm{hf}}\right) \mathrm{d} B_{\mathrm{hf}}$ is the fraction of probe atoms whose field is between $B_{\mathrm{hf}}$ and $B_{\mathrm{hf}}+\mathrm{d} B_{\mathrm{hf}}$. Lorentzian lineshapes of full width at half maximum of $0.22 \mathrm{~mm} / \mathrm{s}$ were used in this procedure. The average isomer shifts with respect to metallic bcc iron at room temperature and magnetic line intensity ratios were obtained by means of an iterative spectrum fitting.

$\mathrm{X}$-ray diffraction experiments (XRD) were carried out at $\mathrm{RT}$ with $\mathrm{CuK}_{\alpha}$ radiation $(\lambda=0.154184 \mathrm{~nm})$ in a Bragg-Brentano geometry diffractometer, with a monochromator and a Ni filter. The goniometer step was 0.05 .

Transformation into the sigma phase was promoted by isothermal annealing in vacuum at $973 \mathrm{~K}$.

Magnetization measurements were performed under primary vacuum using an Oxford Instruments vibrating sample magnetometer apparatus, equipped with an oven, spanning the temperature range from 300 to $973 \mathrm{~K}$ with a rate of $30 \mathrm{~K} / \mathrm{min}$. The samples were then maintained at $973 \mathrm{~K}$ for several hours in order to carry out the $\alpha \rightarrow \sigma$ phase transformation. The applied field was $0.5 \mathrm{~T}$.

\section{Results and Discussion}

\subsection{Characterization of the as-prepared samples}

As determined by SEM, typical particles of the 1-FeCr sample have sizes which range from about 40 to $60 \mu \mathrm{m}$ while they range between 20 and $40 \mu \mathrm{m}, 10$ to $50 \mu \mathrm{m}$ and 5 to $20 \mu \mathrm{m}$ for $\mathrm{t}-\mathrm{FeCr}, \mathrm{t}-\mathrm{FeCrSn}{ }_{3}$ and $\mathrm{t}-\mathrm{FeCrSn}_{6}$, respectively. Sample compositions are given in Table 1. The composition dispersion from particle to particle is in all cases less than 0.9 at $\%$.

TEM studies showed that the crystallite sizes range between 5 and $10 \mathrm{~nm}$. These results are in accordance with those obtained with X-ray diffraction [13]. The X-ray diffraction patterns of the samples show a bcc structure with broad peaks. This is due both to strains produced during the mechanically alloying process and to crystallite

Table 1

Average sample compositions ( $\mathrm{u}$ - and $\mathrm{t}$ - mean, respectively, that untreated or hardened vials and balls were used). The 1-FeCr sample is a milled $\mathrm{Fe}_{57} \mathrm{Cr}_{43}$ ingot

\begin{tabular}{ll}
\hline sample & average composition (at\%) \\
\hline $\mathrm{t}-\mathrm{FeCr}$ & $\mathrm{Fe}_{55.5} \mathrm{Cr}_{44.5}$ \\
$\mathrm{t}-\mathrm{FeCrSn}$ & \\
$\mathrm{t}-\mathrm{FeCrSn}$ & $\mathrm{Fe}_{52.0} \mathrm{Cr}_{44.5} \mathrm{Sn}_{3.5}$ \\
l-FeCr & $\mathrm{Fe}_{49.3} \mathrm{Cr}_{44.5} \mathrm{Sn}_{6.2}$ \\
u-FeCrSn & $\mathrm{Fe}_{56.8} \mathrm{Cr}_{43.2}$ \\
u-FeCrSn & $\mathrm{Fe}_{48.4} \mathrm{Cr}_{45.1} \mathrm{Sn}_{6.5}$ \\
u-FeCrSn & $\mathrm{Fe}_{47.2} \mathrm{Cr}_{44.3} \mathrm{Sn}_{8.5}$ \\
\hline
\end{tabular}


sizes. The mean sizes of crystallites are similar in all samples but the lattice strains are greater in the u-samples. The smallest strains were found in samples ground from the ingot (l-FeCr). In the u-samples a significant fraction of a metallic amorphous phase was found that crystallizes at a temperature around $873 \mathrm{~K}$ when heated at a rate of $10 \mathrm{~K} / \mathrm{min}$ [13]. Homogeneous solid solutions or metallic amorphous phases were reported to be the dynamical equilibrium phases of mechanically alloyed $\mathrm{Fe}_{100-x} \mathrm{Cr}_{x}$ alloys according to the composition and to the milling conditions. An amorphous phase was observed to form for $x \approx 0.70$ by Xia et al. $[14,15]$. The formation of the amorphous phase observed in the u-samples may be related to different milling conditions, due in particular to different volumes $V_{\mathrm{u}}$ and $V_{\mathrm{t}}$ of powder particles trapped between colliding balls in the case of untreated tools and of hardened ones, respectively ([16] and references therein) but the favourable role of oxygen must also be considered [17].

The bcc lattice parameters of the samples obtained from XRD measurements showed that the solubility of $\mathrm{Sn}$ is increased from about 2 at\% in coarse-grained alloys $[11,18]$ to about 6 at\% in the mechanically alloyed samples (Fig. 1).

${ }^{57} \mathrm{Fe}$ Mössbauer spectra at room temperature for the $\mathrm{t}$-samples and the 1-FeCr sample (Fig. 2) were fitted considering hyperfine magnetic field distributions. The mean hyperfine fields and isomer shifts obtained from the fits are $\left.16.8 \mathrm{~T},-0.018 \mathrm{~mm} / \mathrm{s}(\mathrm{t}-\mathrm{FeCrSn})_{6}\right), 15.3 \mathrm{~T}$, $\left.-0.036 \mathrm{~mm} / \mathrm{s}(\mathrm{t}-\mathrm{FeCrSn})_{3}\right), 13.3 \mathrm{~T},-0.067 \mathrm{~mm} / \mathrm{s}(\mathrm{t}-\mathrm{FeCr})$ and $17.8 \mathrm{~T},-0.073 \mathrm{~mm} / \mathrm{s}(\mathrm{l}-\mathrm{FeCr})$. These spectra confirm the extension of the solubility of $\mathrm{Sn}$ in the ground alloys as compared to the equilibrium alloys. The decrease of the mean hyperfine field and the increase of the isomer shift with the increase of Sn content is attributed to the progressive increase of the number of Sn atoms which are nearest neighbours of Fe atoms.

${ }^{119} \mathrm{Sn}$ Mössbauer spectra of the u-samples at $160 \mathrm{~K}$ were analysed by superimposing a paramagnetic component to a magnetic one (Fig. 3). The paramagnetic peak, which is present in all the u-samples, has an isomer shift of about $1.55 \mathrm{~mm} / \mathrm{s}$ (relative to $\mathrm{CaSnO}_{3}$ ), and is due to $\mathrm{Sn}$ atoms in an amorphous phase [13]. In the case of $\mathrm{u}-\mathrm{FeCrSn}_{6}$, the paramagnetic phase corresponds to $10 \%$ of the total spectral area and the hyperfine parameters of the magnetic phase are $\left\langle B_{\mathrm{hf}}\right\rangle=3.3 \mathrm{~T}$ and $\langle\mathrm{IS}\rangle=1.57 \mathrm{~mm} / \mathrm{s}$. The mean hyperfine parameters for $\mathrm{t}-\mathrm{FeCrSn}_{6}$ are $\left\langle B_{\mathrm{hf}}\right\rangle=4.43 \mathrm{~T}$ and $\langle\mathrm{IS}\rangle=1.51 \mathrm{~mm} / \mathrm{s}$. These values are similar to those obtained for coarse-grained alloys [18]. The ${ }^{119} \mathrm{Sn}$ Mössbauer

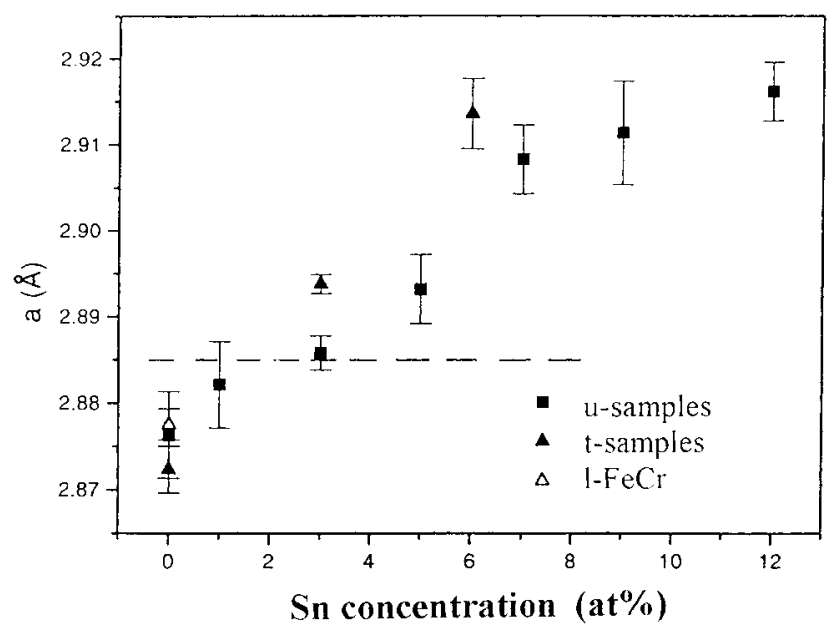

Fig. 1. Lattice parameters of bcc mechanically alloyed samples. The lines indicate the range of lattice parameters found for coarse-grained alloys 


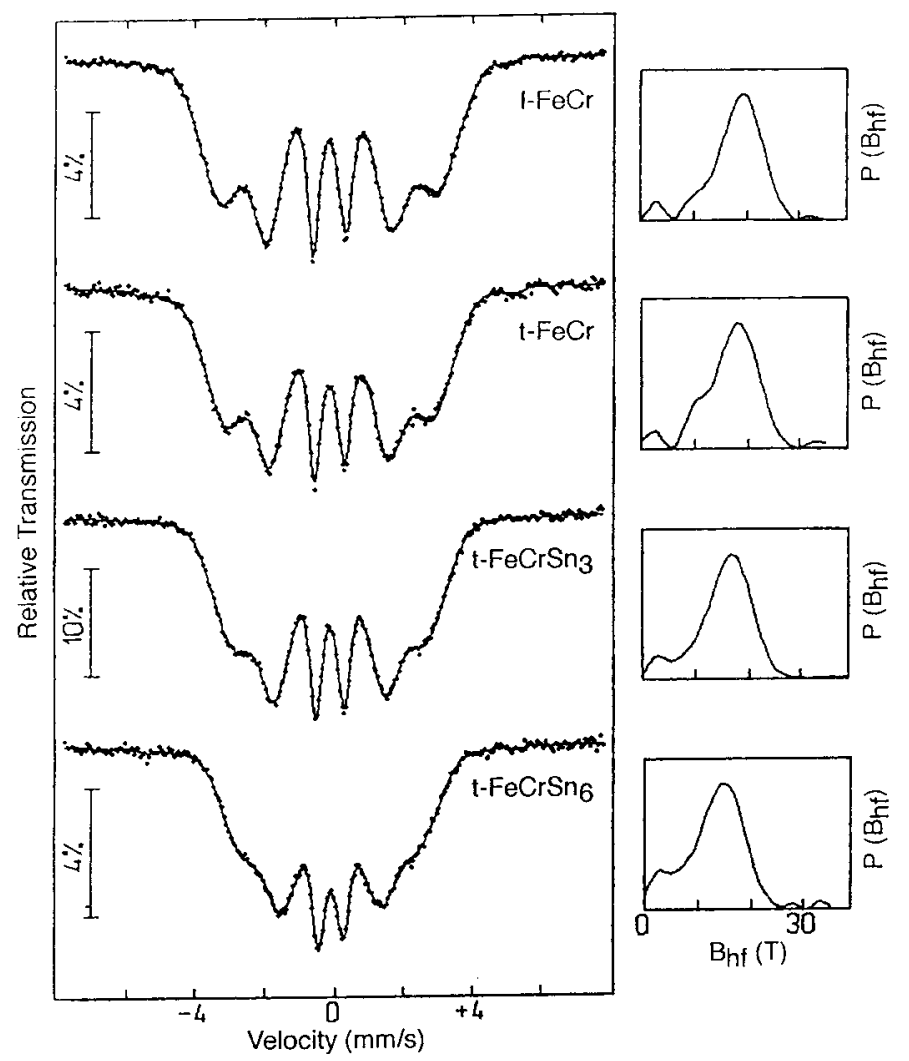

Fig. 2. Room temperature ${ }^{57} \mathrm{Fe}$ Mössbauer spectra and corresponding hyperfine field distributions for as-milled alloys

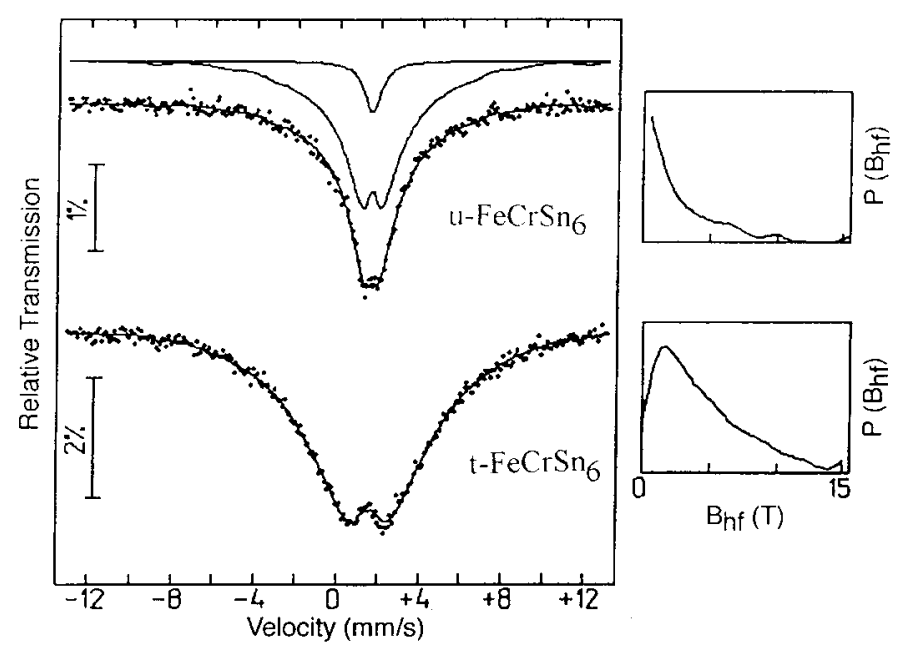

Fig. 3. ${ }^{119}$ Sn Mössbauer spectra obtained at $160 \mathrm{~K}$ and hyperfine field distributions for some asmilled alloys 
spectrum of $\mathrm{t}-\mathrm{FeCrSn}{ }_{6}$ at $160 \mathrm{~K}$ confirms that $\mathrm{Sn}$ is dissolved in the $\mathrm{Fe}-\mathrm{Cr}$ alloy, as it is magnetic and as no $\beta$-Sn nor other subspectrum is found.

\subsection{Alpha-sigma phase transformation}

\subsubsection{Morphological and structural characterization}

TEM observations and X-ray diffraction patterns (Fig. 4) show the formation of the grains of alpha phase and the precipitation of sigma phase during annealing at $973 \mathrm{~K}$. Sigma phase precipitates are observed by TEM for instance after $10 \mathrm{~min}$ of annealing of the $\mathrm{t}-\mathrm{FeCrSn}_{6}$ sample at $973 \mathrm{~K}$. This is not observed by X-ray diffraction measurements as shown in Table 3. The diffraction patterns show that the $\alpha \rightarrow \sigma$ transforma-
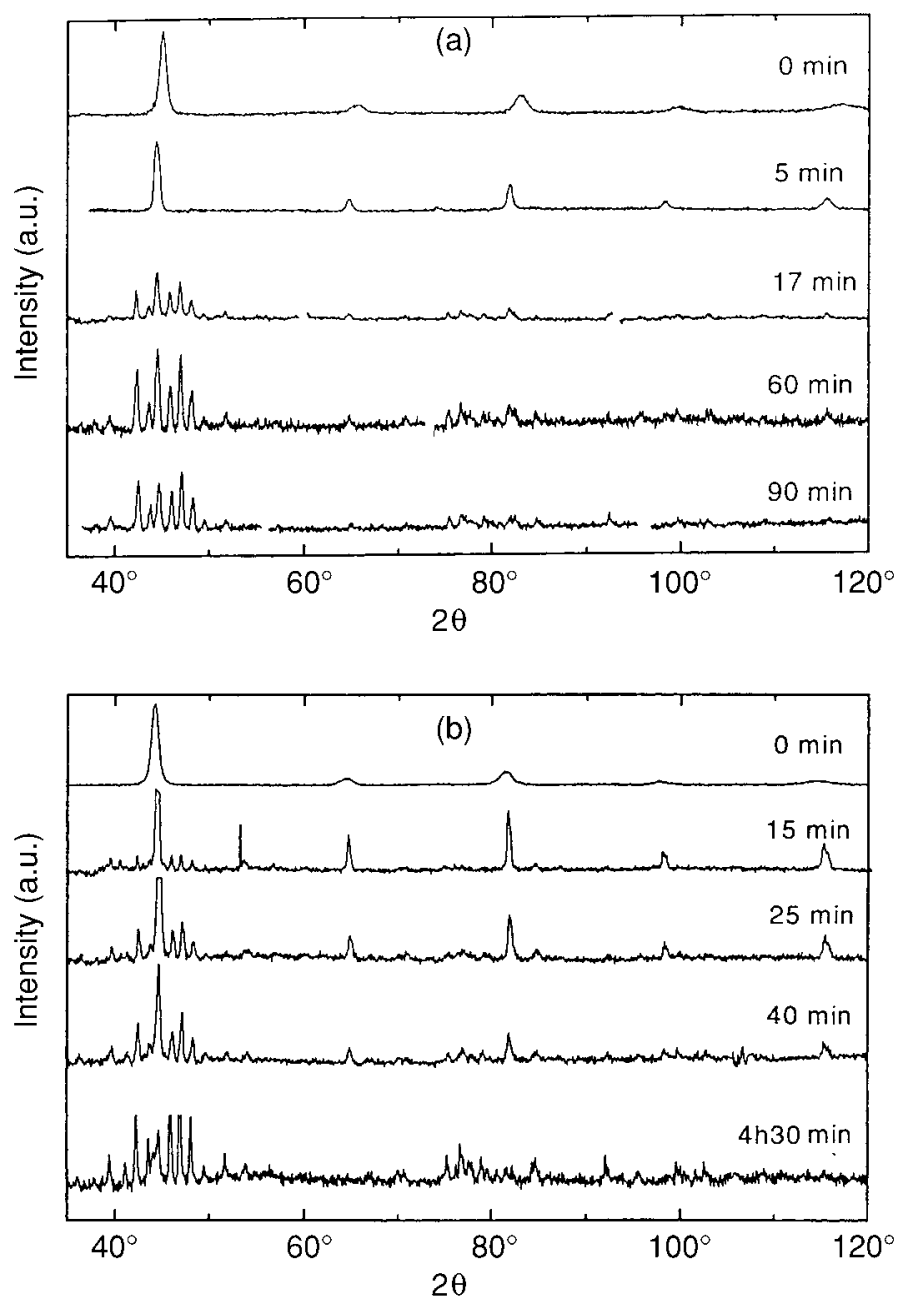

Fig. 4. X-ray diffractograms $\left(\mathrm{CuK}_{\alpha}\right.$ radiation, $\left.\lambda=0.158184 \mathrm{~nm}\right)$ recorded at room temperature: a) for $\mathrm{t}-\mathrm{FeCr}$ annealed at $973 \mathrm{~K}$ for different periods, and b) for $\mathrm{t}-\mathrm{FeCrSn}{ }_{6}$ annealed at $973 \mathrm{~K}$ for different periods 
tion is faster in $\mathrm{t}-\mathrm{FeCr}$ than in $\mathrm{t}-\mathrm{FeCrSn}{ }_{6}$ as found also for tin-free and tin- containing coarse-grained alloys [3]. However, in the case of nanostructured samples the transformation times are of the order of minutes instead of the several hours needed in the case of coarse-grained alloys.

XRD measurements in $\mathrm{u}$-samples show that the $\alpha \rightarrow \sigma$ transformation is even faster than that it is in t-samples and that the transformation occurs more rapidly in the samples with higher Sn content. These are the samples with a large fraction of amorphous phase whose crystallization produces a great number of defects that act as nucleation sites of the sigma phase.
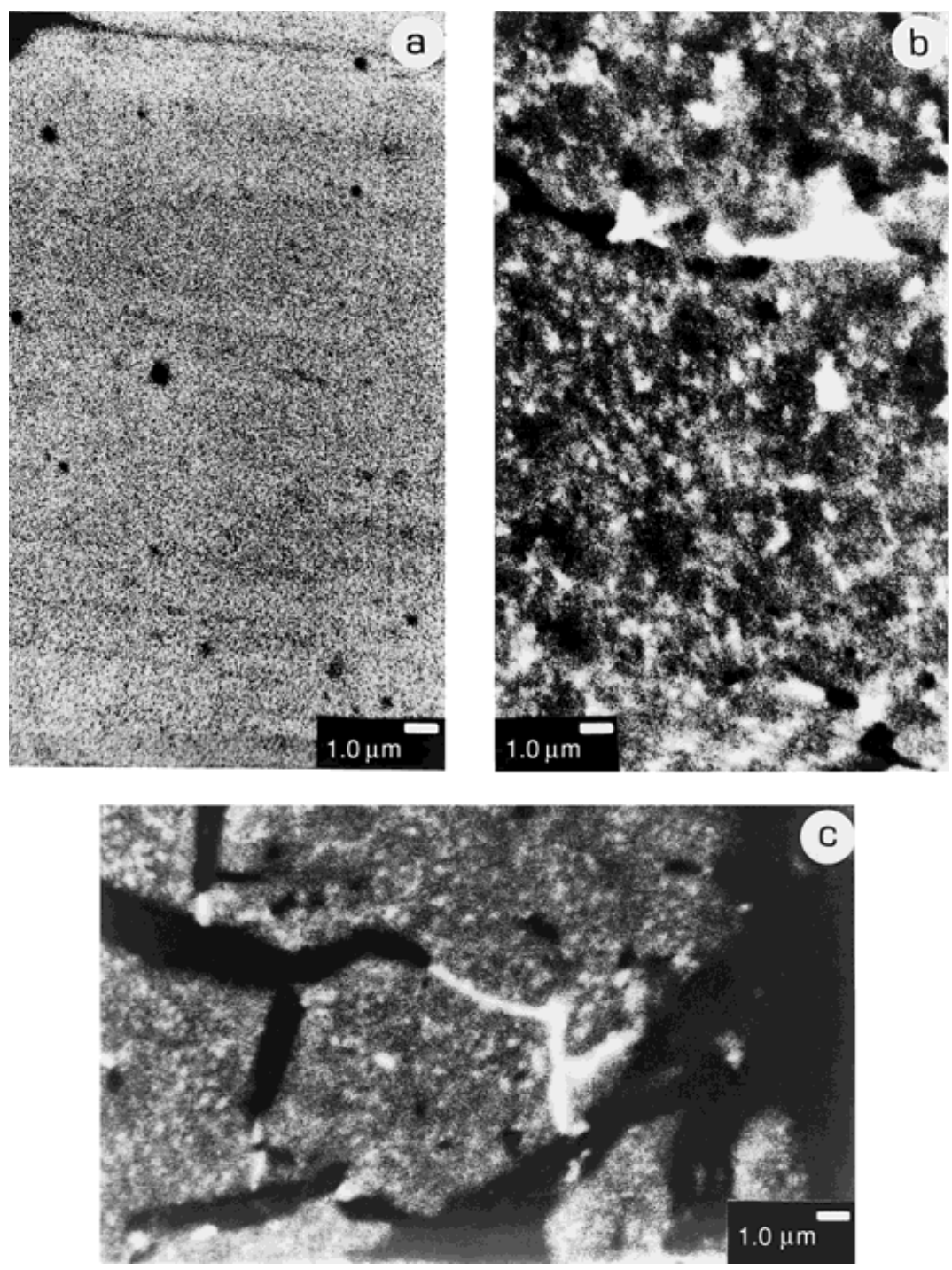

Fig. 5. SEM micrographs obtained in backscattered-electron mode of $\mathrm{u}-\mathrm{FeCrSn}_{6}$ : a) as milled, b) and c) annealed at $973 \mathrm{~K}$ for $35 \mathrm{~min}$. The white spots in b) and c) correspond to precipitated Sn 
Table 2

Mean crystallite size $\langle d\rangle$ and strain $\varepsilon$ of $\alpha$ - and $\sigma$-phases, obtained from a t-FeCr sample annealed at $973 \mathrm{~K}$ for different periods

\begin{tabular}{|c|c|c|c|c|c|c|c|c|c|}
\hline & \multicolumn{8}{|c|}{ annealing time at $973 \mathrm{~K}(\mathrm{~min})$} & \\
\hline & 0 & 5 & 17 & 27 & 34 & 60 & 90 & 150 & \\
\hline$\alpha$-phase & $\begin{array}{c}10 \\
0.6\end{array}$ & $\begin{array}{c}15 \\
0.5\end{array}$ & $\begin{array}{l}21 \\
0.4\end{array}$ & $\begin{array}{l}35 \\
0.3\end{array}$ & $\begin{array}{l}- \\
-\end{array}$ & $\begin{array}{l}- \\
-\end{array}$ & $\begin{array}{l}- \\
-\end{array}$ & $\begin{array}{l}- \\
-\end{array}$ & $\begin{array}{l}\langle d\rangle(\mathrm{nm}) \\
\varepsilon(\%)\end{array}$ \\
\hline$\sigma$-phase & $\begin{array}{l}- \\
-\end{array}$ & $\begin{array}{l}- \\
-\end{array}$ & $\begin{array}{l}29 \\
0.4\end{array}$ & $\begin{array}{l}36 \\
0.24\end{array}$ & $\begin{array}{l}31 \\
0.23\end{array}$ & $\begin{array}{l}25 \\
0.5\end{array}$ & $\begin{array}{l}46 \\
0.5\end{array}$ & $\begin{array}{l}27 \\
0.2\end{array}$ & $\begin{array}{l}\langle d\rangle(\mathrm{nm}) \\
\varepsilon(\%)\end{array}$ \\
\hline
\end{tabular}

Figure 5 shows SEM micrographs, obtained in the backscattered-electron mode, of the $\mathrm{u}-\mathrm{FeCrSn}{ }_{6}$ sample, as milled (Fig. 5a) and annealed at $973 \mathrm{~K}$ for $35 \mathrm{~min}$ (Fig. 5b and c). The first micrograph confirms the homogeneity of the solid solution. The others reveal the precipitation of $\mathrm{Sn}$ or of $\mathrm{Sn}$-rich phases, due to the annealing treatment at $973 \mathrm{~K}$. The microstructure of the latter sample makes it impossible to isolate regions without Sn. To analyse phase compositions, we have used an electron beam of low energy $(10 \mathrm{keV})$ to reduce the interaction volume and achieve a lateral resolution of about $0.4 \mathrm{~nm}$. The results show the presence of a phase with a low Sn content (about 2 at\%) of the darker regions in the micrograph, while the lighter regions have Sn concentration ranging from 5 to 10 at\%. The white spots correspond to $\mathrm{Sn}$ precipitates. The composition of the phase with a low Sn content (2 at \%) agrees with the $\sigma$-phase composition, as found in coarse-grained samples: $(46.5 \pm 0.3)$ at $\% \mathrm{Cr}$ and $(1.4 \pm 0.3)$ at $\%$ Sn [3].

Tables 2 and 3 give the crystallite size and lattice strain of the alpha and sigma phases, as determined by the Williamson-Hall method [19], for the t-FeCr and t-FeCrSn 6 samples annealed at $973 \mathrm{~K}$ for different periods. One can observe an increase of the size of $\alpha$-phase crystallites and a decrease of their lattice strains with annealing time. In the $\sigma$-phase, despite fluctuations, there seems to be a trend to a decrease of grain size for long annealing times.

The mean isomer shift, $\langle\mathrm{IS}\rangle=-0.166 \mathrm{~mm} / \mathrm{s}$, obtained for the sigma phase in $\mathrm{t}-\mathrm{FeCr}$ is slightly smaller than the values determined for coarse-grained alloys with similar compositions: $-0.197 \mathrm{~mm} / \mathrm{s}$ for $\mathrm{Fe}-43.9$ at $\% \mathrm{Cr}$ [18], $-0.1816 \mathrm{~mm} / \mathrm{s}$ for $\mathrm{Fe}-45.5$ at\% $\mathrm{Cr}$ [20] and $-0.180 \mathrm{~mm} / \mathrm{s}$ for $\mathrm{Fe}-43.9$ at\% Cr [21]. The $\langle I S\rangle$ values obtained for the samples with $\mathrm{Sn}$ and the l-FeCr sample are similar to those obtained for t-FeCr.

Table 3

Mean crystallite size $\langle d\rangle$ and strain $\varepsilon$ of $\alpha$ - and $\sigma$-phases, obtained for a t-FeCrSn 6 sample annealed at $973 \mathrm{~K}$ for different periods

\begin{tabular}{|c|c|c|c|c|c|c|c|c|c|}
\hline & \multicolumn{8}{|c|}{ annealing time at $973 \mathrm{~K}(\mathrm{~min})$} & \\
\hline & 0 & 10 & 15 & 25 & 40 & 60 & 210 & 270 & \\
\hline$\alpha$-phase & $\begin{array}{l}9 \\
0.7\end{array}$ & $\begin{array}{c}17 \\
0.5\end{array}$ & $\begin{array}{c}24 \\
0.2\end{array}$ & $\begin{array}{c}30 \\
0.2\end{array}$ & $\begin{array}{c}31 \\
0.1\end{array}$ & $\begin{array}{l}- \\
-\end{array}$ & $\begin{array}{l}- \\
-\end{array}$ & $\begin{array}{l}- \\
-\end{array}$ & $\begin{array}{l}\langle d\rangle(\mathrm{nm}) \\
\varepsilon(\%)\end{array}$ \\
\hline$\sigma$-phase & $\begin{array}{l}- \\
-\end{array}$ & $\begin{array}{l}- \\
-\end{array}$ & $\begin{array}{l}- \\
-\end{array}$ & $\begin{array}{c}16 \\
1.4\end{array}$ & $\begin{array}{l}23 \\
0.9\end{array}$ & $\begin{array}{l}37 \\
0.2\end{array}$ & $\begin{array}{c}20 \\
0.2\end{array}$ & $\begin{array}{l}30 \\
0.4\end{array}$ & $\begin{array}{l}\langle d\rangle(\mathrm{nm}) \\
\varepsilon(\%)\end{array}$ \\
\hline
\end{tabular}


Table 4

Unit cell parameters and volume of the tetragonal $\sigma$-phase precipitated in samples annealed at $973 \mathrm{~K}$ during the indicated periods

\begin{tabular}{|c|c|c|c|c|}
\hline sample & $\begin{array}{l}\text { annealing time } \\
\text { at } 973 \mathrm{~K}\end{array}$ & $\begin{array}{l}a \\
(\AA)\end{array}$ & $\begin{array}{l}c \\
(\AA)\end{array}$ & $\begin{array}{l}\text { unit cell volume } \\
\left(\AA^{3}\right)\end{array}$ \\
\hline $\mathrm{t}-\mathrm{FeCr}$ & $2 \mathrm{~h} 30 \mathrm{~min}$ & $8.774 \pm 0.017$ & $4.595 \pm 0.031$ & $353.7 \pm 3.1$ \\
\hline $\mathrm{t}-\mathrm{FeCrSn} n_{3}$ & $4 \mathrm{~h}$ & $8.786 \pm 0.020$ & $4.549 \pm 0.022$ & $351.1 \pm 3.3$ \\
\hline $\mathrm{t}-\mathrm{FeCrSn} \mathrm{n}_{6}$ & $4 \mathrm{~h} 30 \mathrm{~min}$ & $8.797 \pm 0.004$ & $4.557 \pm 0.006$ & $352.6 \pm 0.8$ \\
\hline
\end{tabular}

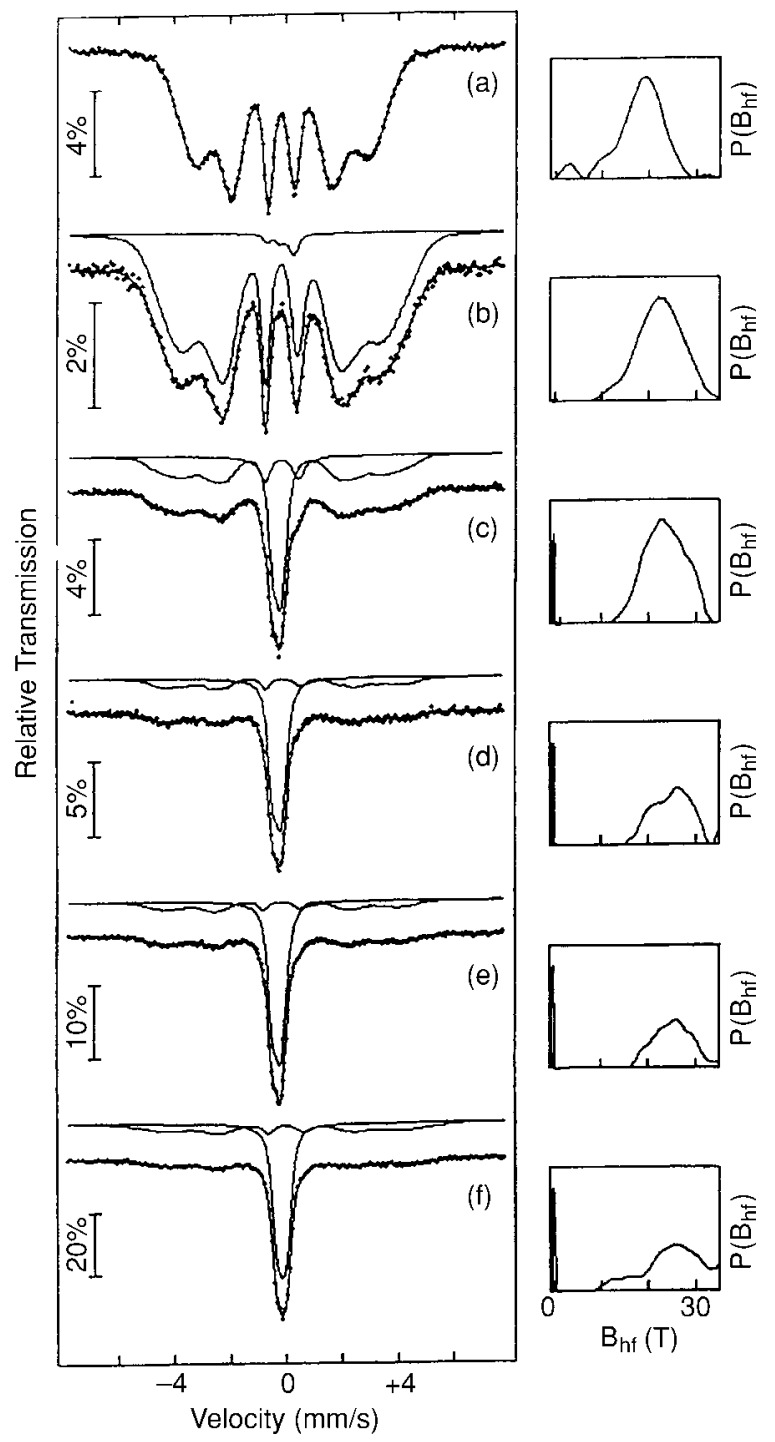

Table 4 presents the lattice parameters of the tetragonal $\sigma$ phase in samples annealed for different periods. The values obtained for $a$ and $c$ agree with those determined by Bergman and Schoemaker for $\sigma$-FeCr with 46.5 at $\%$ of $\mathrm{Cr}$ [22]: $a=(8.7995 \pm$ $0.0004) \AA$ and $c=(4.5442 \pm$ $0.0002) \AA$.

In spite of the extension in $\mathrm{Sn}$ solubility obtained by mechanical alloying, the lattice parameters of the $\sigma$-phase do not change with Sn content in agreement with a narrow composition range of this phase and with a low Sn content as discussed above and in [3].

Figures 6, 7 and 8 show roomtemperature ${ }^{57} \mathrm{Fe}$ Mössbauer spectra of ball-milled $1-\mathrm{FeCr}$

Fig. 6. Room temperature ${ }^{57} \mathrm{Fe}$ Mössbauer spectra of 1-FeCr annealed for: a) $0 \mathrm{~min}$, b) $2 \mathrm{~min}$, c) $10 \mathrm{~min}$, d) $35 \mathrm{~min}$, e) $1 \mathrm{~h} 30 \mathrm{~min}$ and f) $10 \mathrm{~h}$. The values of $A_{\sigma}$ are b) $2 \%$, c) $43 \%$, d) $66 \%$, e) $69 \%$ and f) $71 \%$. The hyperfine field distributions from the remaining bcc alloy are also shown 


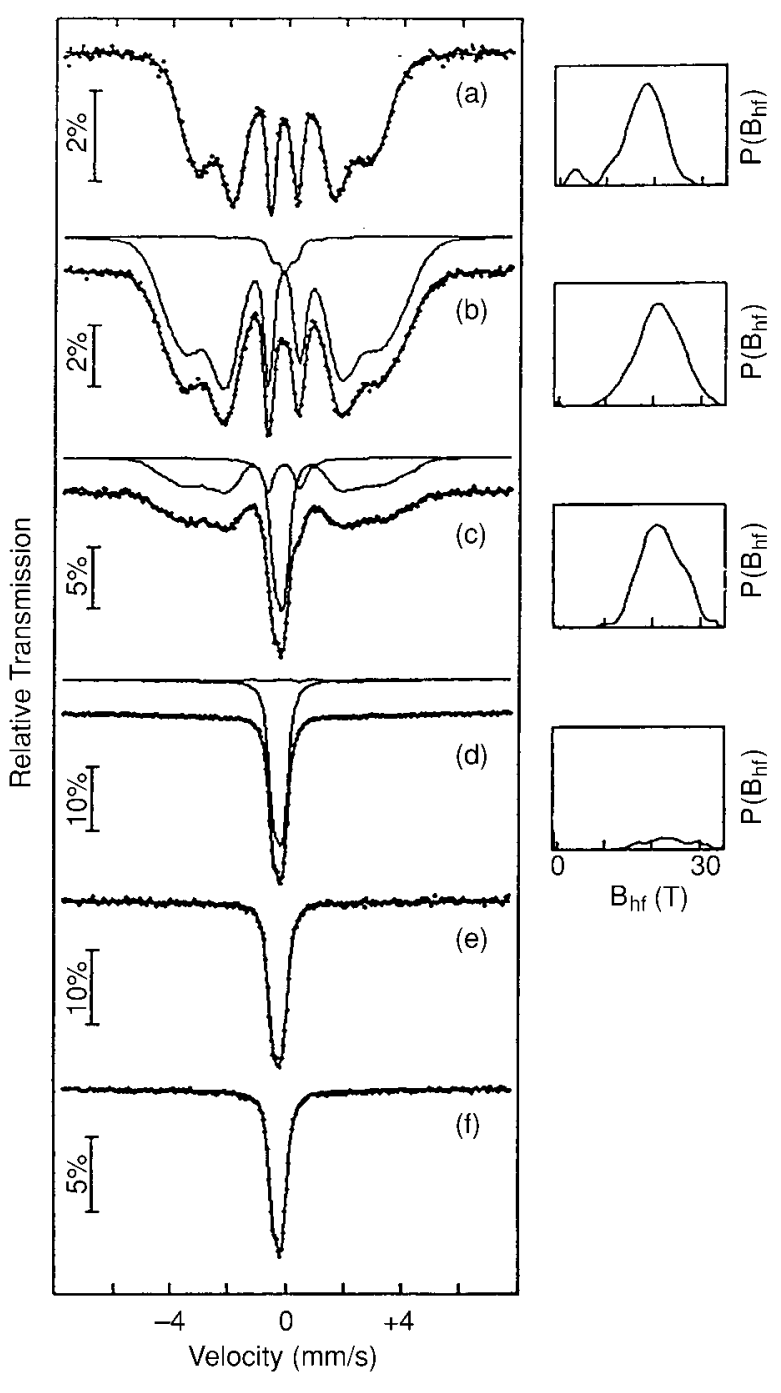

Fig. 7. Room temperature ${ }^{57} \mathrm{Fe}$ Mössbauer spectra of $\mathrm{t}-\mathrm{FeCr}$ annealed for: a) $0 \mathrm{~min}$, b) $1 \mathrm{~min}$, c) $3 \mathrm{~min}$, d) $10 \mathrm{~min}$, e) $1 \mathrm{~h} 30 \mathrm{~min}$ and f) $10 \mathrm{~h}$. The values of $A_{\sigma}$ are b) $4 \%$, c) $37 \%$, d) $89 \%$, e) $100 \%$ and f) $100 \%$. The hyperfine field distributions from the remaining bcc alloy are also shown

$\mathrm{t}-\mathrm{FeCr}$ and $\mathrm{t}-\mathrm{FeCrSn} \mathrm{C}_{6}$, annealed at $973 \mathrm{~K}$ for the periods indicated, respectively.

${ }^{119}$ Sn Mössbauer spectra obtained at $160 \mathrm{~K}$ for the $\mathrm{t}-\mathrm{FeCrSn} \mathrm{C}_{6}$ sample annealed at $973 \mathrm{~K}$ are presented in Fig. 9 and Table 5 gives the results obtained from their fits.

${ }^{57} \mathrm{Fe}$ spectra include a broad magnetic component whose fraction decreases with annealing time and a paramagnetic contribution which becomes rapidly predominant. The sigma phase is not the only phase that is formed during annealing of ternary alloys at $973 \mathrm{~K}$. The residual magnetic contribution to the ${ }^{57} \mathrm{Fe}$ Mössbauer spectrum after $38.5 \mathrm{~h}$ of annealing of $\mathrm{t}-\mathrm{FeCrSn}_{6}$ (Fig. $8 \mathrm{~g}$ ) is ascribed to a tin-containing intermetallic compound whose contribution is also found in ${ }^{119} \mathrm{Sn}$ spectra. The fraction of a tin-rich intermetallic com-

pound is expected to be low from the available amount of tin. The latter compound will thus give very weak contributions to XRD patterns and to ${ }^{57} \mathrm{Fe}$ Mössbauer spectra. It is thus difficult to identify this intermetallic compound from its sole contribution to ${ }^{119} \mathrm{Sn}$ spectra but it may tentatively be attributed to a compound of the $(\mathrm{Fe}, \mathrm{Cr})_{3} \mathrm{Sn}_{2}$ type. Its spectral parameters (Table 5), which differ from those of the other compounds of the $\mathrm{Fe}-\mathrm{Sn}$ phase diagram, are indeed similar, except for isomer shifts, to those found for the two equipopulated tin sites $\operatorname{Sn}(1)$ and $\operatorname{Sn}(2)$ of the intermetallic compound $\mathrm{Fe}_{3} \mathrm{Sn}_{2}$ [23]. The latter are: $B_{1}=(5.8 \pm 0.2) \mathrm{T}, \mathrm{QS}_{1}=(1.62 \pm 0.06) \mathrm{mm} / \mathrm{s}, \mathrm{IS}_{1}=(2.02 \pm$ $0.04) \mathrm{mm} / \mathrm{s}, B_{2}=(1.4 \pm 0.1) \mathrm{T}, \mathrm{QS}_{2}=(-1.05 \pm 0.06) \mathrm{mm} / \mathrm{s}, \mathrm{IS}_{2}=(1.89 \pm 0.04) \mathrm{mm} / \mathrm{s}$ at $250 \mathrm{~K}$. The isomer shifts found here are larger than those of $\mathrm{Fe}_{3} \mathrm{Sn}_{2}$ even when uncertainties on $\mathrm{IS}_{1}$ and $\mathrm{IS}_{2}$ (Table 5), which are of the order of 0.2 and $0.1 \mathrm{~mm} / \mathrm{s}$, respectively, are taken into account. Such differences may be attributed to the influence of $\mathrm{Cr}$ 


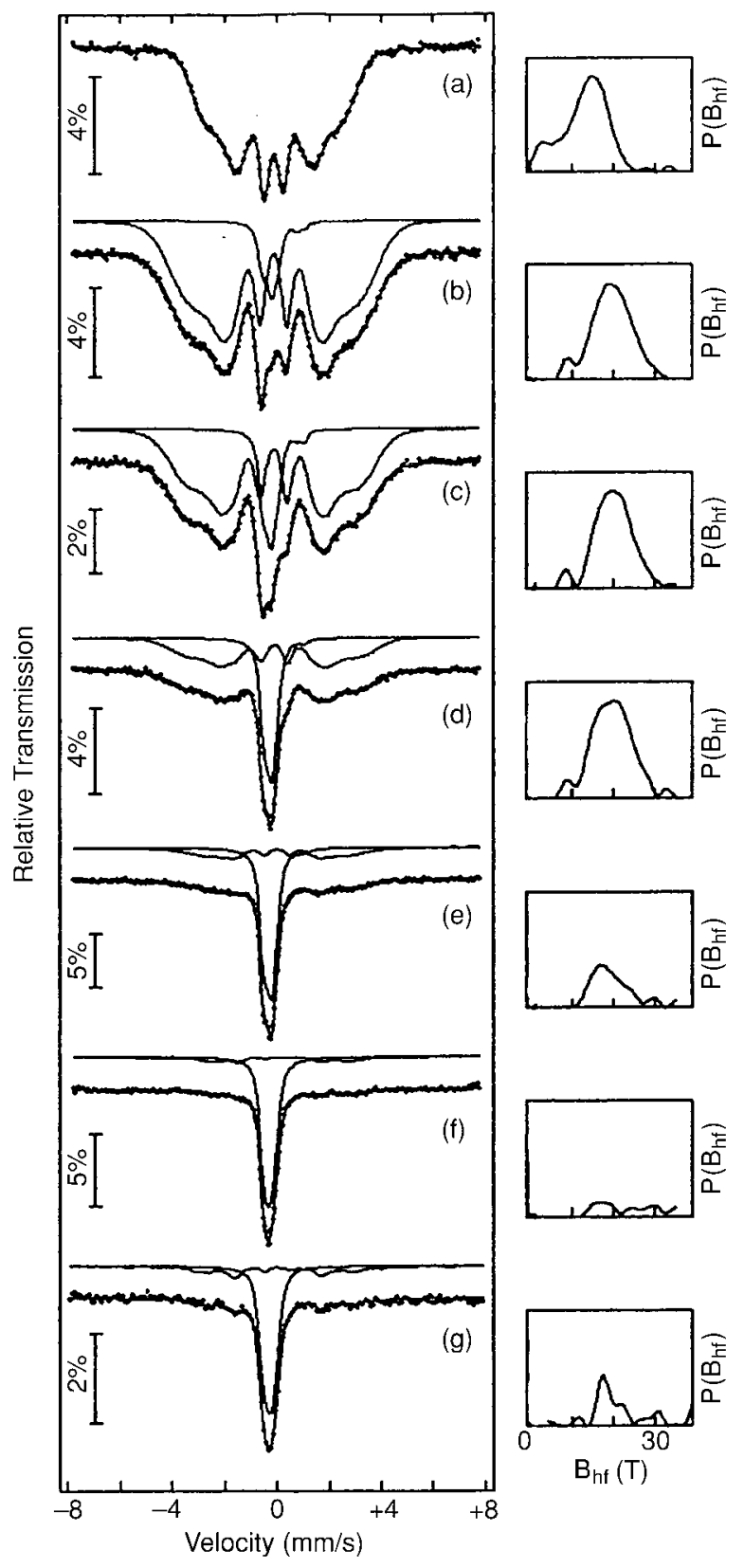

Fig. 8. Room temperature ${ }^{57} \mathrm{Fe}$ Mössbauer spectra of $\mathrm{t}-\mathrm{FeCrSn}{ }_{6}$ annealed for: a) $0 \mathrm{~min}$, b) $10 \mathrm{~min}$, c) $15 \mathrm{~min}$, d) $25 \mathrm{~min}, \mathrm{e}) 1 \mathrm{~h}, \mathrm{f}) 10 \mathrm{~h}$ and(g) $38 \mathrm{~h}$ $30 \mathrm{~min}$. The values for $A_{\sigma}$ are b) $10 \%$, c) $19 \%$, d) $41 \%$, e) $66 \%$, f) $85 \%$ and g) $76 \%$. The hyperfine field distributions of the remaining bcc alloy are also shown

which is also expected to modify tin hyperfine fields, more particularly those of $\mathrm{Sn}(1)$ atoms which are located in metal-tin planes [23]. This may also account for the reduced intensity of site 1 as compared to site 2 (Table 5).

\subsubsection{Kinetics and transformation mechanisms}

The high density of grain boundaries created by grinding accelerates the $\sigma$-phase precipitation when compared to the precipitation in the starting coarse-grained alloy. Indeed, the ball-milled $1-\mathrm{FeCr}$ alloy contains already $67 \%$ of $\sigma$-phase after $1 \mathrm{~h}$ at $973 \mathrm{~K}$ while the latter fraction is only $12 \%$ in the coarse-grained alloy [3]. The sigma phase formation is delayed in $\mathrm{t}-\mathrm{FeCrSn} \mathrm{C}_{6}$ as compared to $\mathrm{t}-\mathrm{FeCr}$ as also found for coarse-grained alloys [3]. The transformation is almost complete after $10 \mathrm{~min}$ in $\mathrm{Sn}$-free t-FeCr and only after $10 \mathrm{~h}$ in the sample with 6 at $\%$ Sn. This effect was also observed in coarse-grained samples, although the transformation times were much longer: $5 \mathrm{~h}$ and $54 \mathrm{~h}$ for samples without $\mathrm{Sn}$ and with 5 at\% of $\mathrm{Sn}$, respectively. The kinetics of precipitation of the $\sigma$-phase in the l-FeCr and t-FeCr samples cannot be compared directly because the former has a composition that lies outside the $\sigma$-phase domain in the $\mathrm{FeCr}$ phase diagram.

Impurities contained in the as-milled alloys might influence the precipitation rate of the $\sigma$-phase. An early experiment was performed with an alloy prepared by mechanical 


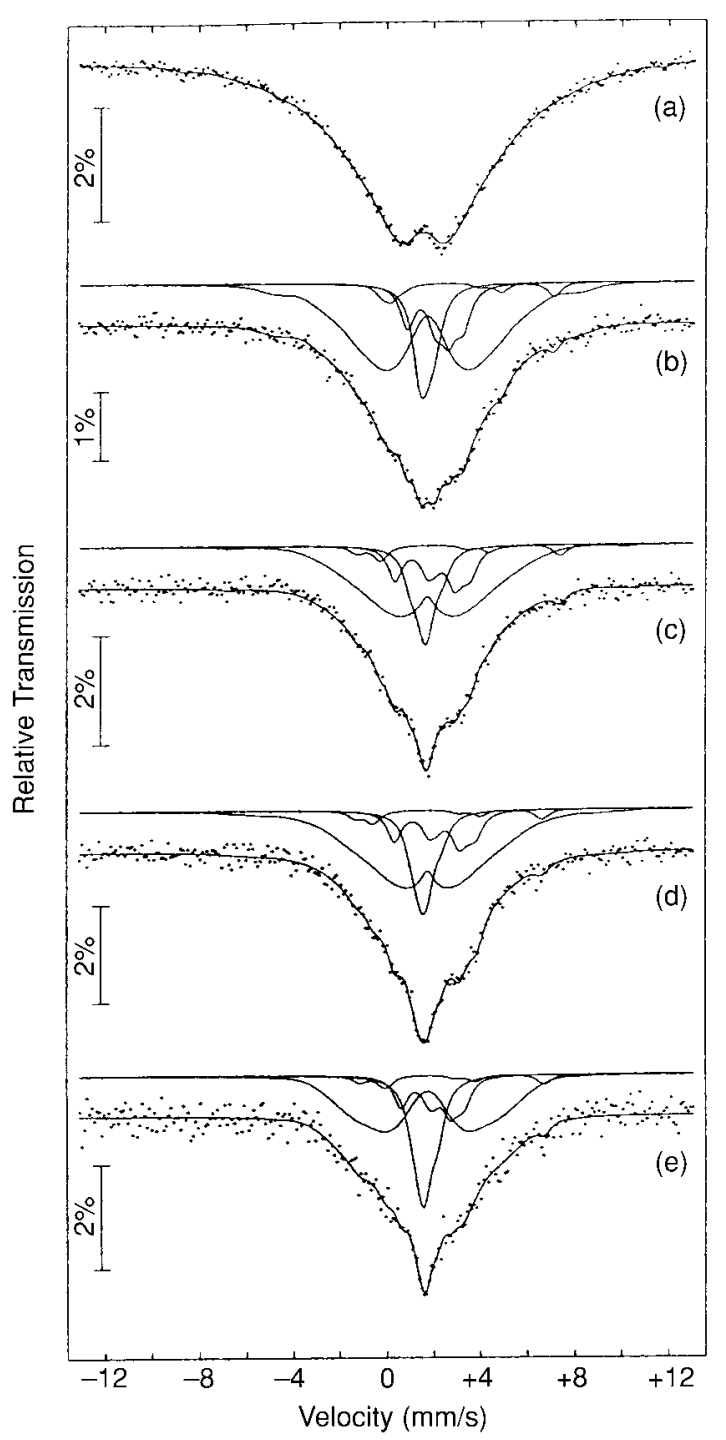

Fig. 9. ${ }^{119} \mathrm{Sn}$ Mössbauer spectra of $\mathrm{t}-\mathrm{FeCrSn} \mathrm{C}_{6}$ at $160 \mathrm{~K}$ : as-milled a) and annealed at $973 \mathrm{~K}$ for: b) $10 \mathrm{~min}, \mathrm{c}$ ) $40 \mathrm{~min}$, d) $4 \mathrm{~h} 30 \mathrm{~min}$, e) $10 \mathrm{~h}$

alloying in the conditions described in Section 2.1 during $8 \mathrm{~h}$ and subsequently annealed at $1173 \mathrm{~K}$ during $33 \mathrm{~h}$ to produce a coarse-grained alloy. The composition of the alloy is determined by microprobe analysis to be $\mathrm{Fe}_{56.3} \mathrm{Cr}_{43.7}$, a composition close to that of t-FeCr (Table 1). The kinetics of the sigma phase precipitation at $973 \mathrm{~K}$ was then followed and found to be similar to that of a conventional alloy prepared with pure starting elements. The kinetics is for instance completed after $30 \mathrm{~h}$ of annealing at $973 \mathrm{~K}$. This result indicates that impurities are not the main factor of the strong increase of of $\sigma$-phase precipitation rate in the as-milled nanocrystalline alloys. The transformation time obtained for the nanostructured alloys is of the same order of magnitude as that of the coldrolled coarse-grained $\mathrm{Fe}-\mathrm{Cr}$ alloys with 45.5 at $\% \mathrm{Cr}$ studied by Japa et al. [24] where the transformation is complete after $1 \mathrm{~h}$ at $973 \mathrm{~K}$. The fast $\alpha \rightarrow \sigma$ transformation would unfortunately be difficult to follow in t-FeCr with in-situ Mössbauer investi-

gations similar to those recently performed by Cieslak et al. for $\mathrm{Fe}_{53.8} \mathrm{Cr}_{46.2}-x$ at $\% \mathrm{Ti}$ $(x<3)$ with a typical recording time of $15 \mathrm{~min}$ for the successive spectra [5,6]. The latter experiment would be worth being performed in nanograined alloys which contain tin. The fraction of $\sigma$-phase was determined, with an error of about $6 \%$, from the relative spectral areas, as the Lamb-Mössbauer factors are similar in both phases and the volume fractions of the two phases are also approximately equal [18]. A ratio $R=f_{\alpha} / f_{\alpha}$ $=1.15$ was measured by Cieslak et al. at $973 \mathrm{~K}$ [5] who show that the Johnson-MehlAvrami parameters which are found when assuming that $R=1$ do not differ significantly from those found for $R=1.15$. The fraction of $\sigma$-phase, $A_{\sigma}$, is represented in Fig. $10 \mathrm{~b}$ for t-samples as a function of annealing time at $973 \mathrm{~K}$. Figure $10 \mathrm{a}$ represents, for comparision, the fraction of $\sigma$-phase in coarse-grained alloys. 
Table 5

Spectral parameters of the $\alpha$ - and $\sigma$-phases and of the magnetic sites considered in the

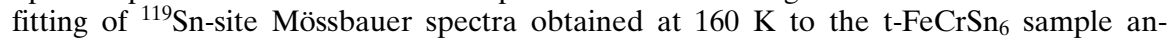
nealed at $973 \mathrm{~K}$ for different periods. The phases percentages are also given for each spectrum. The isomer shifts are relative to $\mathrm{CaSnO}_{3}$ at RT

\begin{tabular}{lllll}
\hline annealing time & $\begin{array}{l}\left\langle I_{\alpha}\right\rangle \\
(\mathrm{mm} / \mathrm{s})\end{array}$ & $\% \sigma$ & $\begin{array}{l}\left\langle B_{\alpha}\right\rangle \\
(\mathrm{T})\end{array}$ & $\begin{array}{l}\left\langle I_{\alpha}\right\rangle \\
(\mathrm{mm} / \mathrm{s})\end{array}$ \\
\hline $0 \mathrm{~min}$ & - & - & 4.4 & 1.51 \\
$10 \mathrm{~min}$ & 1.67 & 17 & 4.3 & 1.65 \\
$40 \mathrm{~min}$ & 1.66 & 25 & 3.5 & 1.67 \\
$4 \mathrm{~h} 30$ & 1.62 & 23 & 3.6 & 1.65 \\
$10 \mathrm{~h}$ & 1.64 & 27 & 4.1 & 1.67 \\
\hline
\end{tabular}

\begin{tabular}{lllllllll}
\hline $\begin{array}{l}\text { annealing } \\
\text { time }\end{array}$ & $\begin{array}{l}B_{1} \\
(\mathrm{~T})\end{array}$ & $\begin{array}{l}\mathrm{IS}_{1} \\
(\mathrm{~mm} / \mathrm{s})\end{array}$ & $\begin{array}{l}\mathrm{QS}_{1} \\
(\mathrm{~mm} / \mathrm{s})\end{array}$ & $(\%)_{1}$ & $\begin{array}{l}\mathrm{B}_{2} \\
(\mathrm{~T})\end{array}$ & $\begin{array}{l}\mathrm{IS}_{2} \\
(\mathrm{~mm} / \mathrm{s})\end{array}$ & $\begin{array}{l}\mathrm{QS}_{2} \\
(\mathrm{~mm} / \mathrm{s})\end{array}$ & $(\%)_{2}$ \\
\hline $10 \mathrm{~min}$ & 5.1 & 2.82 & 1.30 & 6 & 1.3 & 2.22 & -0.92 & 17 \\
$40 \mathrm{~min}$ & 5.6 & 2.56 & 1.96 & 6 & 1.8 & 2.16 & -1.06 & 17 \\
$4 \mathrm{~h} 30$ & 5.3 & 2.18 & 1.65 & 5 & 2.0 & 2.28 & -1.11 & 15 \\
$10 \mathrm{~h}$ & 4.9 & 2.32 & 2.03 & 6 & 1.5 & 2.12 & -0.92 & 17 \\
\hline
\end{tabular}

The mechanism of precipitation of the sigma phase in nanostructured alloys with an extended Sn solubility is not the same as that found in coarse-grained alloys with an amount of tin which is larger than the equilibrium solubility. The slowing-down mechanism is indeed not the decrease of the density of nucleation sites which results from the decoration of grain boundaries, edges and corners by tin precipitates as found in the latter coarse-grained alloys [11], but a limitation of the growth rate of the sigma-phase. The growth of $\sigma$-phase grains whose $\mathrm{Sn}$ content at equilibrium is low from a Sn-rich metastable solid solution requires first a rejection of tin which is accompanied by the formation and growth of Sn-rich phases. This slowing-down effect is as expected much
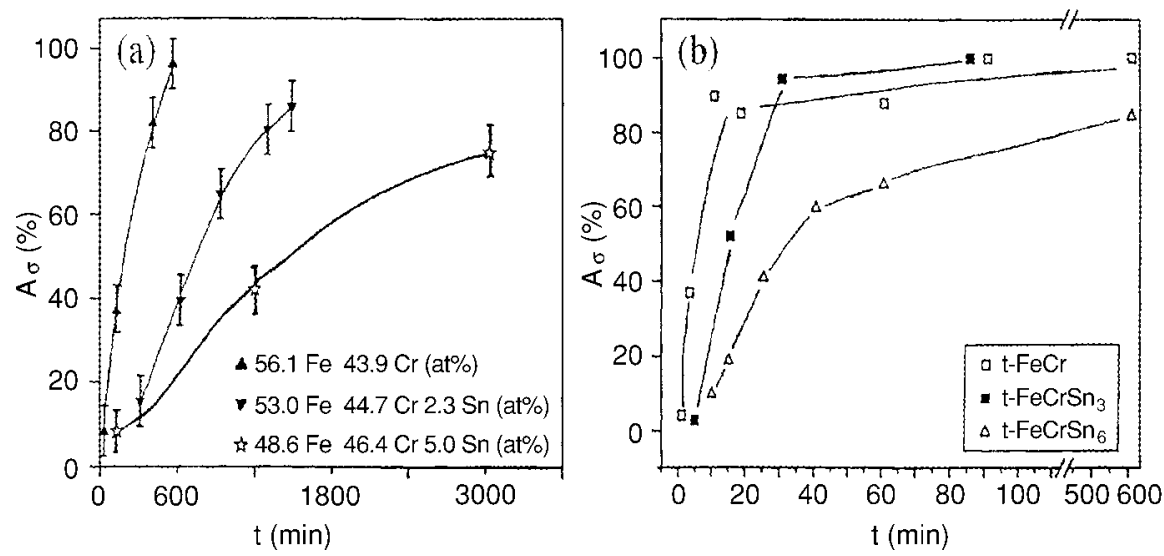

Fig. 10. Fraction of $\sigma$-phase, $A_{\sigma}$, in a) as-cast and b) as-milled alloys, as a function of the annealing time at $973 \mathrm{~K}$. The error is about $6 \%$. The lines through the points are guides to the eye 


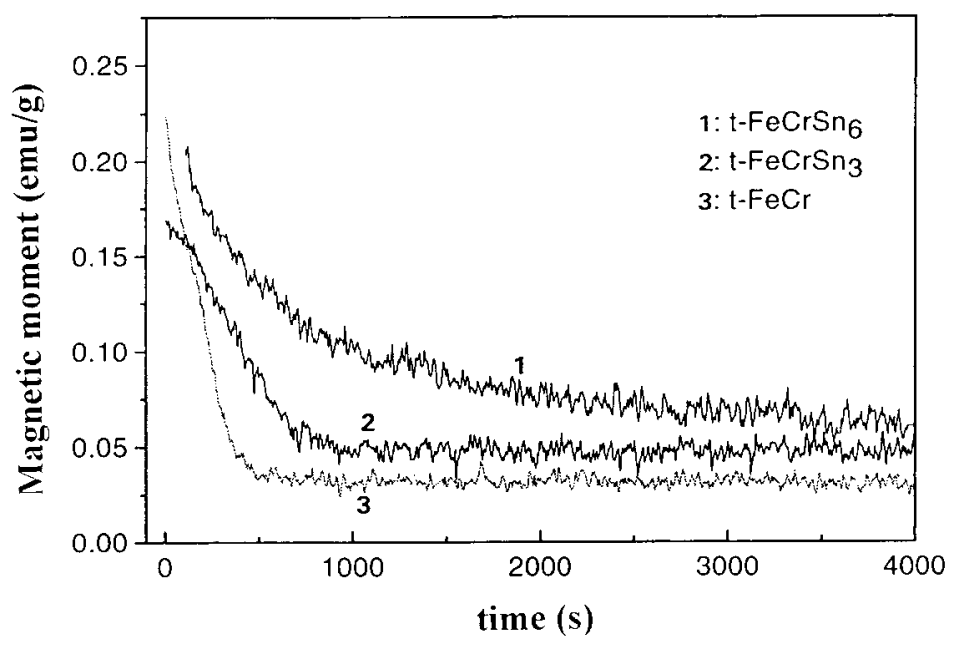

Fig. 11. Magnetization recorded during the annealing at $973 \mathrm{~K}$ of the indicated alloys under an applied field of $0.5 \mathrm{~T}$

stronger for $\mathrm{t}-\mathrm{FeCrSn} n_{6}$ than it is for $\mathrm{t}-\mathrm{FeCrSn}_{3}$ whose tin content is close to the equilibrium solubility (Fig. 10b).

Figure 11 shows the time dependence of the magnetization $M$ of t-samples isothermally annealed at $973 \mathrm{~K}$ in an applied field of $0.5 \mathrm{~T}$. The magnetization decreases as expected during the $\alpha \rightarrow \sigma$ transformation. After annealing, the samples were cooled down to room temperature and characterized by XRD and ${ }^{57} \mathrm{Fe}$ Mössbauer spectroscopy. In the case of $\mathrm{t}-\mathrm{FeCrSn}_{6}$ a residual magnetic contribution was found in the Mössbauer spectrum as expected from the study described above.

The transformation times found from magnetization measurements are about $30 \%$ shorter than the times determined by Mössbauer spectroscopy, because in the former case the heating rate was about $35 \mathrm{~K} / \mathrm{min}$, that is a significant fraction of the characteristic transformation time, while it was about $350 \mathrm{~K} / \mathrm{min}$ in the latter.

The time dependence of the isothermal increase of $A_{\sigma}(t)$, obtained from Mössbauer measurements, has been fitted with a Johnson-Mehl-Avrami equation (JMA) (Fig. 12),

$$
F=1-\exp \left(-(k t)^{n}\right)
$$

Table 6

Values of $n$ and $k$ obtained from RT Mössbauer spectra

\begin{tabular}{lccl}
\hline sample & first step & second step & \\
\hline $\mathrm{t}-\mathrm{FeCr}$ & 1.74 & 0.22 & $n$ \\
& 10.5 & 140 & $k\left(\mathrm{~h}^{-1}\right)$ \\
$\mathrm{t}-\mathrm{FeCrSn3}$ & 2.7 & & $n$ \\
& 3.19 & & $k\left(\mathrm{~h}^{-1}\right)$ \\
$\mathrm{t}-\mathrm{FeCrSn}$ & & & $n$ \\
& 1.60 & 0.20 & $n$ \\
& 1.49 & 1.37 & $k\left(\mathrm{~h}^{-1}\right)$ \\
\hline
\end{tabular}




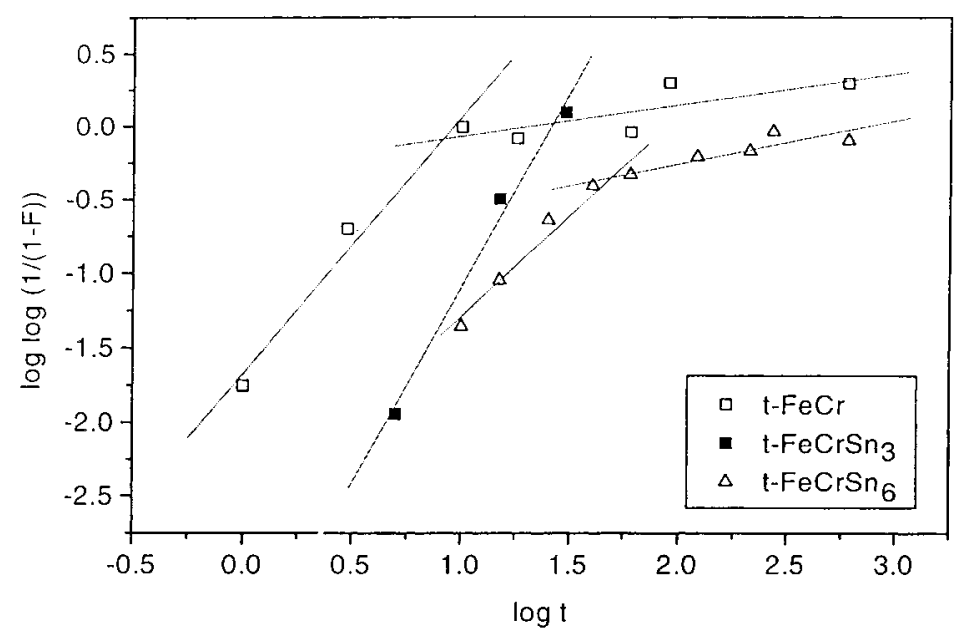

Fig. 12. Johnson-Mehl-Avrami curves fits to $A_{\sigma}(t)$ obtained from ${ }^{57} \mathrm{Fe}$ Mössbauer spectra shown in Fig. 10b

where $F$ is the fraction of $\sigma$-phase precipitated after an isothermal annealing time $t, k$ is a rate constant, and $n$ is the form factor. The fitted values of $n$ and $k$ from $A_{\sigma}(t)$ are given in Table 6. The decrease of the transformation rate with increasing Sn content is reflected in the strong decrease of $k$ (Table 6). Despite its shortcomings, such an approach may be useful more particularly when it provides JMA parameters which agree with those deduced from reasonable assumptions about transformation mechanisms. We notice that a unique value of $n$, close to 2.6, is obtained for the kinetics of the $\sigma$-phase formation in $\mathrm{Fe}_{53.8} \mathrm{Cr}_{46.2}-x$ at $\% \mathrm{Ti}(x<1.1)$ at different temperatures from in-situ Mössbauer studies [5,6]. The transformation rate, given by the factor $k$ (Table 6), decreases drastically with the increase of Sn content in the samples.

Precipitation mechanisms based on diffusion controlled growth with all shapes growing from small dimensions yield values of $n$ which depend on the nucleation rate [25, 26]. The form factor $n$ is equal to or larger than 2.5 for constant or increasing nucleation rate while it ranges between 1.5 and 2.5 for zero or decreasing nucleation rate. The value of $n$ found for $\mathrm{t}-\mathrm{FeCrSn} \mathrm{Cr}_{3}, 2.66$, and for the first steps, 1.74 and 1.60, for the two other alloys are in the expected range. If the JMA equation is relevant to describe the formation kinetics in the $\mathrm{t}-\mathrm{FeCr}$ and $\mathrm{t}-\mathrm{FeCrSn}_{6}$ alloys, it implies a change of the nucleation rates with tin content. For the $\mathrm{Sn}$-free alloy, the nucleation rate may indeed decrease because of grain growth of the alpha phase, while it may decrease because of a decoration of nucleation sites by tin-rich phases in the $\mathrm{Sn}_{6}$ alloy. It is presently difficult to know if the small values of $n$, about 0.2 , in the last transformation step of the $\mathrm{t}-\mathrm{FeCr}$ and $\mathrm{t}-\mathrm{FeCrSn}_{6}$ alloys may be accounted for or not by a mechanism in the frame of a JMA model.

\section{Conclusions}

In mechanically alloyed FeCrSn samples an extension of Sn solubility has been observed, from 2 at $\%$ (in stable coarse-grained alloys) to 6 at $\%$ in the high-energy milling conditions. The precipitation rate of the $\sigma$-phase is higher in the case of mechanically 
alloyed samples than in coarse-grained alloys of the same composition. This is mainly due to the higher fraction of grain boundaries per sample volume in alloys with nanometer-sized grains. The rate of the alpha-sigma transformation decreases significantly with the increase of the Sn content in the latter alloys. Eventual technological applications of such nanostructured alloys will have to take into consideration the fast formation of a sigma phase which has a detrimental effect on mechanical properties and may annihilate the beneficial effect resulting from the strong reduction of grain size.

Acknowledgements This work was partly funded by the Portuguese-French FCCTFrench Embassy in Lisbon collaboration. The authors would also like to thank the Grupo de Estado Sólido do Departamento de Física da Universidade de Coimbra for the availability of X-ray diffraction facilities and the IFIMUP of Faculdade de Ciências da Universidade do Porto for the availability of magnetization measurements.

\section{References}

[1] A. Hishinuma, S. Isozaki, S. Takaki, and K. Abiko, phys. stat. sol. (a) 160, 431 (1997).

[2] K. Yano and K. AвiKo, phys. stat. sol. (a) 160, 449 (1997).

[3] B.F.O. Costa and S.M. Dubiel, phys. stat. sol. (a) 139, 83 (1993).

[4] A. Blachowski, J. Cieslak, and S.M. Dubiel, Phil. Mag. Lett. 79, 87 (1999).

[5] J. Cieslak, S.M. Dubiel, and B. Sepiol, Solid State Commun. 111, 613 (1999).

[6] A. Blachowski, J. Cieslak, S.M. Dubiel, and J. Zukrowski, J. Alloys Comp. 308, 189 (2000).

[7] C.C. Koch, D.G. Morris, K. Lu, and A. Inoue, MRS Bull., February 1999 (p. 54).

[8] L.R. de Araujo Pontes, Ph. D. Thesis, Nancy 1992.

[9] S. Nasu, P.H. Shingu, K.N. Ishihara, and F.E. Fujita, Hyperfine Interact. 55, 1043 (1990).

[10] A.F. Cabrera, F.H. Sanchez, and L.A. Mendoza Zelis, Phys. Rev. B 53, 8378 (1996).

[11] B.F.O. Costa, G. Le CAËr, and N. Ayres de CAMpos, phys. stat. sol. (a) 164, 687 (1997).

[12] G. Le CaËr and J.M. Dubois, J. Phys. E 12, 1083 (1979).

[13] B.F.O. Costa, G. Le Caër, S. Begin-Colin, P.J. Mendes, and N. Ayres de Campos, J. Mater. Proc. Technol. 92-93, 395 (1999).

[14] S.K. Xia, E. Baggio-Saitovitch, F.C. Rizzo Assunçao, and V.A. Pena Rodriguez, J. Phys.: Condensed Matter 5, 2729 (1993).

[15] S.K. Xia, F.C. Rizzo Assunçao, and E. Baggio-Saitovitch, Mater. Sci. Forum 225-227, 459 (1996).

[16] S. Bégin-Colin, T. Girot, G. Le Cä̈r, and A. Mocellin, J. Solid State Chem. 149, 41 (2000).

[17] C. Lemoine, Ph. D. Thesis, Université de Rouen, 2000.

[18] B.F.O. Costa, Ph. D. Thesis, Coimbra, 1998.

[19] G. Williamson and W.H. Hall, Acta Metall. 1, 22 (1952).

[20] S.M. Dubiel and J. Zukrowski, J. Magn. Magn. Mater. 23, 214 (1981).

[21] R.M.C.S. VILAR, Ph. D. Thesis, Orsay, 1983.

[22] B.G. Bergman and D.P. Shoemaker, Acta Cryst. 7, 857 (1954).

[23] G. Le Caër, B. Malaman, L. Häggström, and T. Ericsson, J. Phys. F 9, 1905 (1979).

[24] E.A. Japa, J. Starzynski, and S.M. Dubiel, J. Phys. F 12, L159 (1982).

[25] J.W. Christian, The Theory of Transformations in Metals and Alloys, Part I, Equilibrium and General Kinetic Theory, 2nd edition, Pergamon Press, New York 1981.

[26] J.W. Christian, in: Physical Metallurgy, Ed. R.W. Cahn, North-Holland Publ. Co., Amsterdam 1965 (Chap. 10). 